\title{
Photophobia, CTCAE 5.0
}

National Cancer Institute

\section{Source}

National Cancer Institute. Photophobia, CT CAE 5.0. NCI Thesaurus. Code C146770.

A disorder characterized by fear and avoidance of light. 